\title{
An urgent need for a change in policy revealed by a study on prenatal testing for Duchenne muscular dystrophy
}

\author{
Apollonia TJM Helderman-van den Enden ${ }^{\star, 1,4}$, Kamlesh Madan ${ }^{1}$, Martijn H Breuning ${ }^{1}$, \\ Annemieke $\mathrm{H}$ van der Hout ${ }^{2}$, Egbert Bakker ${ }^{1}$, Christine EM de Die-Smulders ${ }^{3}$ and Hendrika B Ginjaar ${ }^{1}$
}

Prenatal diagnosis for Duchenne muscular dystrophy (DMD) was introduced in the Netherlands in 1984. We have investigated the impact of 26 years (1984-2009) of prenatal testing. Of the 635 prenatal diagnoses, $51 \%$ were males; nearly half (46\%) of these were affected or had an increased risk of DMD. As a result 145 male fetuses were aborted and 174 unaffected boys were born. The vast majority (78\%) of females, now 16 years or older, who were identified prenatally have not been tested for carrier status. Their average risk of being a carrier is $28 \%$. We compared the incidences of DMD in the periods $1961-1974$ and 1993-2002. The incidence of DMD did not decline but the percentage of first affected boys increased from 62 to $88 \%$. We conclude that a high proportion of families with de novo mutations in the DMD gene cannot make use of prenatal diagnosis, partly because the older affected boys are not diagnosed before the age of five. Current policy, widely accepted in the genetic community, dictates that female fetuses are not tested for carrier status. These females remain untested as adults and risk having affected offspring as well as progressive cardiac disease. We see an urgent need for a change in policy to improve the chances of prevention of DMD. The first step would be to introduce neonatal screening of males. The next is to test females for carrier status if requested, prenatally if fetal DNA is available or postnatally even before adulthood. European Journal of Human Genetics (2013) 21, 21-26; doi:10.1038/ejhg.2012.101; published online 6 June 2012

Keywords: carrier testing; Duchenne muscular dystrophy; neonatal screening; preimplantation genetic diagnosis; prenatal diagnosis

\section{INTRODUCTION}

Duchenne muscular dystrophy (DMD), an X-linked recessive disease leading to relentless loss of muscle tissue, is clinically diagnosed around the age of five. ${ }^{1}$ The mean age of survival is 25 years. The incidence of DMD is roughly 1 in 3500 live male births. ${ }^{2}$ Becker muscular dystrophy (BMD), a milder variant of DMD, has an incidence of 1 in 18450 males. De novo mutations account for onethird of the DMD patients. ${ }^{3}$ The importance of prevention has been much emphasized as no curative therapy is available. Women at risk can be offered genetic counseling and carrier testing. Options for carrier women include prenatal diagnosis, preimplantation genetic diagnosis (PGD) or the use of donor eggs. With prenatal diagnosis, no further testing to determine the carrier status is done if the fetus is female. A male fetus is tested by direct analysis for a known familial mutation to determine if he is affected. If a familial mutation is not known, haplotyping is used to determine whether the fetus has a high risk of being affected with DMD or BMD. The birth of these boys can be prevented by terminating the pregnancy. With PGD, either female or unaffected male embryos can be selected and transferred to the uterus. First trimester prenatal diagnosis for dystrophinopathy has been available in the Netherlands since $1984^{4}$ and PGD since $1995 .{ }^{5}$ However, these strategies do not prevent the birth of boys with a de novo mutation. The aim of this study was to determine the effect of genetic counseling and the use of prenatal testing and PGD on the occurrence of DMD and BMD in the Netherlands.

\section{MATERIALS AND METHODS}

Patients

We have used two sets of data, a postnatal cohort 1993-2002 to determine the incidence of DMD and a prenatal cohort 1984-2009 to examine the results of prenatal diagnosis. We have also included the result of PGD in the period 1995-2009.

\section{Incidence}

Most, and from 1997 onwards all, DNA diagnostics for DMD/BMD in the Netherlands has been done in the Laboratory for Diagnostic Genome Analysis at the Leiden University Medical Center. A mutation in the $D M D$ gene has been identified in more than 1000 patients in our laboratory since the start of the service in 1984. The incidence of DMD was determined from the number of DMD males born in the period 1993-2002 from our database in Leiden and from the total number of live male births obtained from Statistics Netherlands (www.cbs.nl). We chose this 10-year period, because before 1993 not all DMD patients were referred to our laboratory for DNA analysis and not all patients born after 2002 had been clinically diagnosed yet. The diagnosis of dystrophinopathy was considered certain only when a mutation that confirmed the clinical diagnosis had been identified. This was done with MLPA and if no deletion or duplication was found, high resolution melting curve analysis ${ }^{6}$ was used.

${ }^{1}$ Center for Human and Clinical Genetics, Leiden University Medical Center, Leiden, The Netherlands; ${ }^{2}$ Department of Genetics, University Medical Center Groningen, Groningen, The Netherlands: ${ }^{3}$ Department of Clinical Genetics, Maastricht University Medical Center, Maastricht, The Netherlands

*Correspondence: Dr ATJM Helderman-van den Enden, Center for Human and Clinical Genetics, Leiden University Medical Center, Einthovenweg 20, 2333 ZC Leiden, The Netherlands. Tel: +31 71 5269810; Fax: +31 71 5268276; E-mail: Paula.Helderman@mumc.nl

4Present address: Department of Clinical Genetics, Maastricht University Medical Center, PO Box 5800, 6202 AZ Maastricht, The Netherlands.

Received 4 October 2011; revised 3 April 2012; accepted 26 April 2012; published online 6 June 2012 
The incidence of DMD in the birth cohort 1993-2002 was compared with the incidence of DMD patients born in the period 1961-1974 in the Netherlands. ${ }^{7}$ We further split the data on incidences from the 10-year period into two 5-year periods: 1993-1997 and 1998-2002 to see if there was a decline in the incidence in the second period with respect to the first. Finally, we examined the family trees for the birth cohort 1993-2002 to determine: (1) the carrier status of the mother, (2) whether the affected boy was the first affected patient in the family and (3) if the boy was not the first affected, whether the oldest affected boy was older than five at the time of the birth of the younger one. We then compared the proportion of first affected patients in this period to the proportion in 1961-1974 to determine if prenatal testing had been used by DMD families to prevent the birth of subsequent affected boys.

Pearson's $\chi^{2}$-test was used to calculate the significance of difference between the incidences.

\section{Prenatal tests and PGD}

Every woman in the Netherlands with an increased risk of having a son with DMD/BMD is offered prenatal testing. PGD is done only upon request. We examined the results of all the prenatal tests done in 26 years (1984-2009) and PGD in 15 years of (1995-2009). The prenatal data are from the laboratories in Leiden and the University Medical Center Groningen. Prenatal diagnosis was done in Groningen also after 1997 in women from families wherein the mutation had been identified there earlier. We recorded the date, the type and the outcome of the test and the place of residence of the pregnant woman. Tests performed on samples from outside the Netherlands were excluded from the analysis. The PGD data on DMD/BMD cases was obtained from Maastricht University Medical Center, where all the PGD in the Netherlands are carried out

\section{RESULTS}

\section{Incidence}

In the 10-year period (1993-2002) 216 boys with DMD were born. With the exception of one boy born in 1994, none of them had been tested prenatally. The clinical diagnosis in all the 216 boys was confirmed by postnatal DNA analysis. The incidence of DMD was about 1 in 4700 male live births (for the exact figures and confidence intervals see Table 1). The incidence reported for the period 1961-1974 is about 1 in 4200 male live births ${ }^{7}$ (see Table 1). There was no significant difference between the incidences in these two periods $(P=0.227)$. There was also no significant difference $(P=0.114)$ between the incidences in the two 5 -year periods, 1993-1997 (1:4200) and 1998-2002 (1:5200).

\section{Percentage of first affected patients in the DMD families}

Of the 216 boys born with DMD in the period 1993-2002, 189 (88\%) were the first affected patient in the family (95\% CI: 83-92\%). Analysis of maternal lymphocytes showed that 98/189 had a carrier mother and in 91/189 the mutation had arisen de novo, but mosaicism was not excluded in the latter group. In 27/216 (12\%) families there was an older affected family member. One of the 27 was tested prenatally, the parents accepted the $33 \%$ risk indicated by

Table 1 Incidences of Duchenne

\begin{tabular}{lrrc}
\hline Period & $\begin{array}{c}\text { Number of } \\
\text { male births }\end{array}$ & $\begin{array}{c}\text { DMD } \\
\text { patients }\end{array}$ & $\begin{array}{c}\text { DMD incidence } \\
\text { (95\% Cl) }\end{array}$ \\
\hline 1993-1997 & 493769 & 117 & $1: 4220(3573-5154)$ \\
$1998-2002$ & 518210 & 99 & $1: 5234(4373-6518)$ \\
$1993-2002$ & 1011979 & 216 & $1: 4685(4134-5406)$ \\
1961-1974 (van Essen et al7) & 1673791 & 397 & $1: 4215$ (3738-4831) \\
\hline Abbreviations: Cl, confidence interval; DMD, Duchenne muscular dystrophy.
\end{tabular}

haplotyping and an affected boy was born in 1994. The remaining 26/27 families were not known to us before the birth of the second boy; in 12 of these, the older affected boy was younger than 5 years.

In the cohort of $1961-1974,62 \%$ (95\% CI: $57-66 \%)$ of the boys with DMD did not have an affected DMD relative. ${ }^{7}$ This implies that $62 \%$ were the first affected in the family, in contrast to the above mentioned $88 \%$ in the period 1993-2002.

\section{Prenatal diagnosis}

Figure 1 shows the results of 635 prenatal samples, including 28 from Groningen, referred for DMD/BMD between 1 January 1984 and 31 December 2009. There were 322 (51\%) male fetuses, 290 (46\%) female and in 23 (about 4\%) testing was not completed. For details see Figure 1. Figure 2 shows the number of female and male fetuses identified per year. The decreasing number of females in recent years can be attributed to the increasing use of maternal blood for fetal sex determination.

Male fetuses. Figure 1 shows that 147 of the 322 male fetuses (46\%) were affected or had an increased risk of having DMD/BMD. The number of these males found per year is shown in Figure 3. Figure 4 shows that the number of tests based on haplotyping has gradually reduced over the years as the number of cases identified by direct mutation analysis has increased. However, haplotyping is still used if no DNA is available, because the index patient is deceased or if prenatal testing is done in cases without a familial mutation. The pregnancy was terminated in 145 of the 147 cases of affected or at risk fetuses and two affected boys were born. The first is the above mentioned boy born in 1994. The second, born in 1995, had BMD and the pregnancy was continued on grounds that all three affected family members were wheelchair bound only after the age of 50 .

There were 175 male fetuses with no increased risk (Figure 1) and 174 unaffected boys were born. There was one false-negative result where a deletion was missed in 1989 by Southern blotting and multiplex PCR and an affected boy, born in 1990, was diagnosed in 1993. Further investigation revealed that the fetal DNA had been contaminated with 5-10\% DNA from another person but we were unable to trace where or when the contamination had taken place. This was before contamination tests were implemented in our routine diagnostic laboratory in 1993.

Female fetuses. The carrier status of a female is usually determined postnatally at the age of 16 or later. In general, therefore, no molecular testing is done if a fetus is found to be a female. We divided the 290 females into two groups: those that were diagnosed before and after 1 January 1993. The 111 girls that were diagnosed before 1993 are now between 16 and 26 years old (see Figure 1). Only 24 of the 111 have been tested for the familial mutation, at an average age of 17.5 years (Figure 1). This means that $87 / 111$ (78\%) have not yet been tested. The average risk of being a carrier for these girls is 28\% (Figure 1). Their mothers are either proven carriers, have an increased risk determined by haplotyping or are potential germ-line mosaics. $^{8}$

As an exception to the rule, 6 of the 179 females diagnosed after 1993 were tested before adulthood, 3 prenatally and 3 postnatally. Two fetuses were tested because they were at a risk of being affected as they were $45, \mathrm{X} / 46, \mathrm{XX}$ mosaics. The mother in the third case was afraid that she might be a germ-line mosaic and did not want a carrier daughter. One girl was tested at 2 because of delay in motor development. Two girls were tested at the request of the girls and their parents, one at the age of 11 and the other at 16 . 

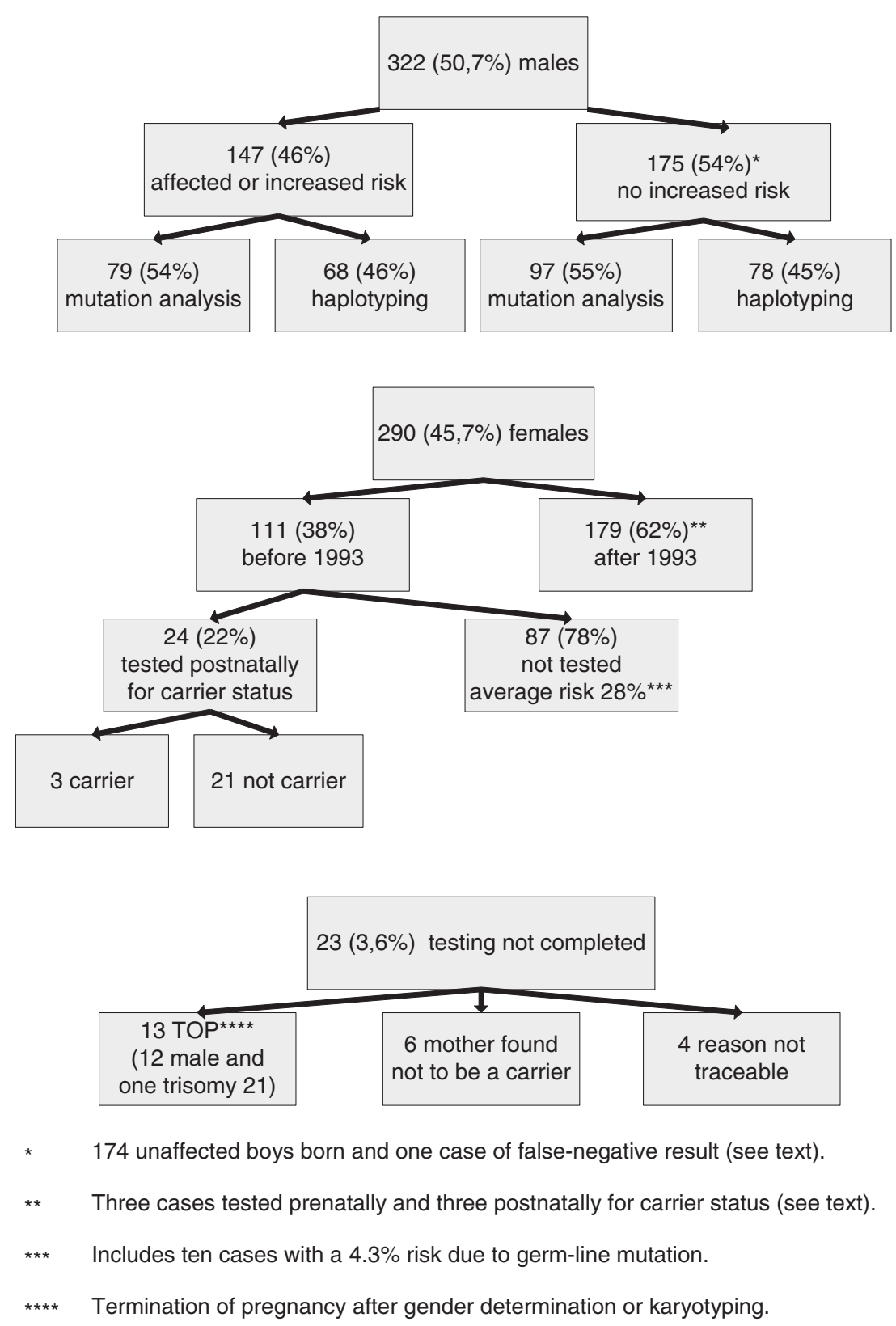

Figure 1 Results of 635 prenatal diagnoses in the period 1984-2009.

Preimplantation genetic diagnosis for dystrophinopathies

Sixty-six couples were referred for PGD for a dystrophinopathy in the period 1995-2009. Most withdrew following extensive genetic counseling; only 14 couples received the treatment with a total of $31 \mathrm{IVF} /$ PGD treatment cycles. The gender was determined using fluorescence in-situ hybridization in all cycles and one or two female embryos were transferred to the uterus. These treatments resulted in the birth of seven healthy girls, three singletons and two sets of twins.

\section{DISCUSSION}

\section{Effect of prenatal testing on the incidence of DMD}

Our study has shown no significant difference in the incidence of DMD between the birth cohorts 1961-1974 (1:4200) ${ }^{7}$ and 1993-2002 (1:4700), or between the two 5-year periods 1993-1997 (1:4200) and 1998-2002 (1:5200). Similar studies in Denmark and Canada have also shown no decrease in the incidence in the last three decades, 9,10 but the incidence in Australia has declined. ${ }^{11}$

It should be noted that the methods by which the data were obtained in the two periods were different. DMD patients in the birth cohort 1961-1974 were diagnosed at a time when molecular testing and immunohistochemical analysis of dystrophin in muscle tissue were not yet possible. ${ }^{7}$

\section{Effect of prenatal testing on known families}

Prenatal testing has provided women in DMD families the possibility of preventing the birth of an affected child. In the period of 26 years, 145 male fetuses that were affected or had a high risk of dystrophinopathy were aborted.

The most significant positive effect of prenatal testing in this period was the birth of 174 unaffected boys in DMD/BMD families. The parents in these cases have been spared the emotional burden of 


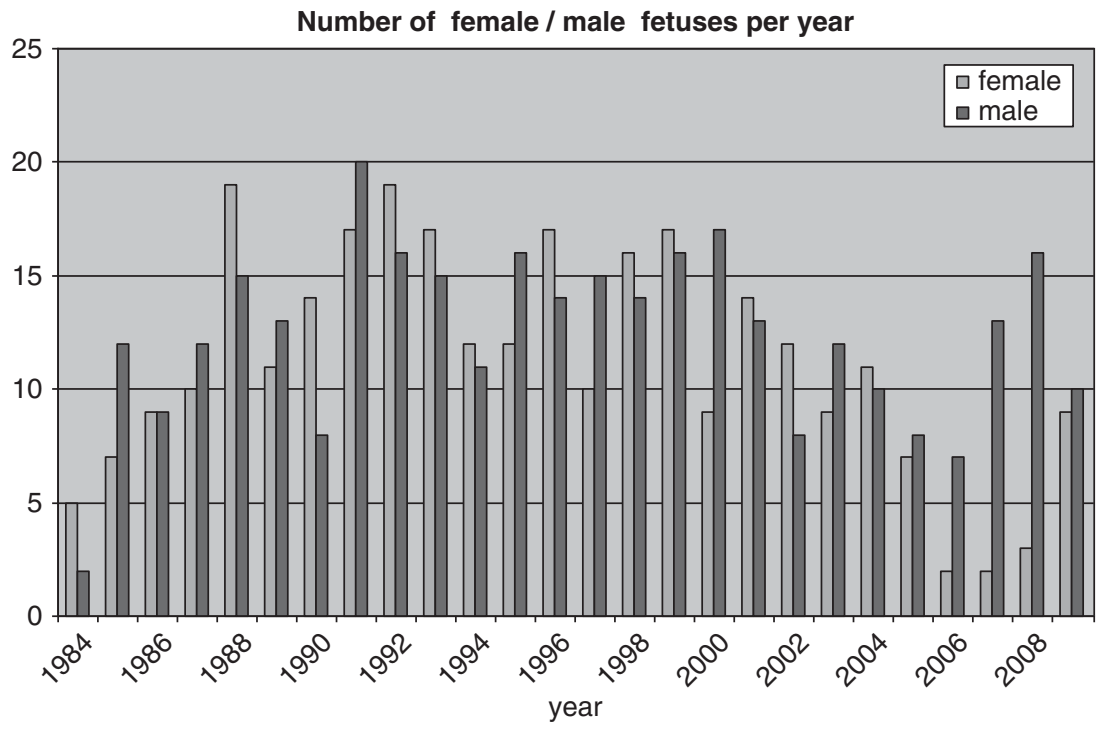

Figure 2 The number of female/male fetuses per year.

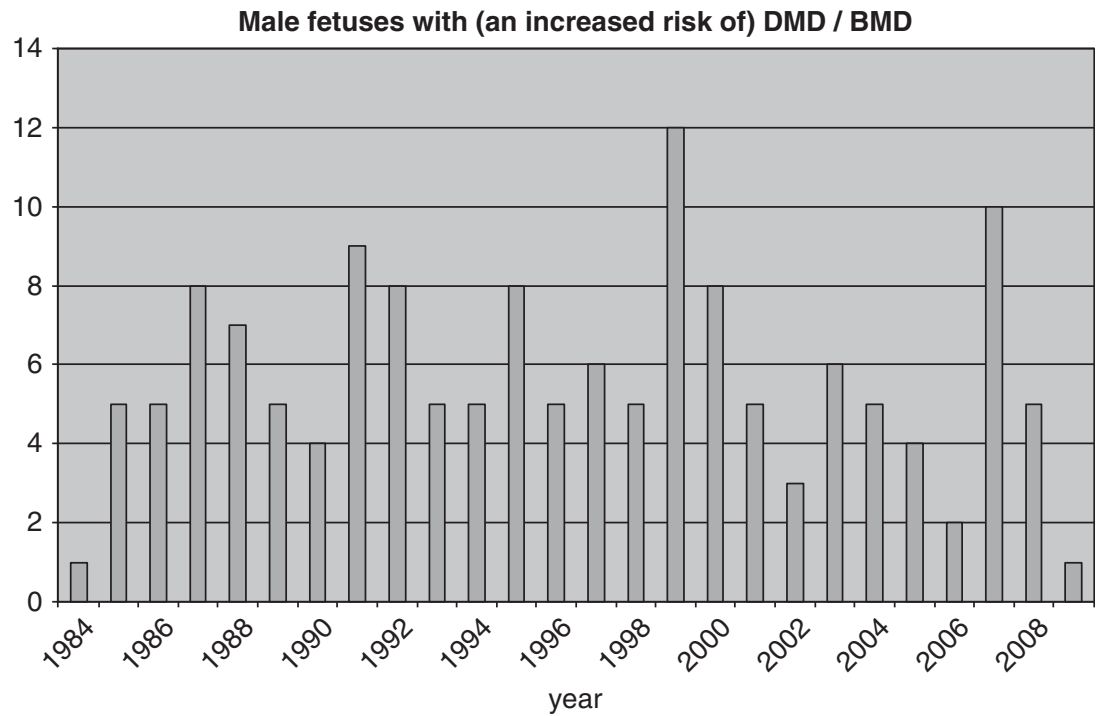

Figure 3 The number of male fetuses with or at an increased risk of having DMD/BMD per year in the period 1984-2009.

having to abort a possibly healthy boy, which was always the major drawback of prenatal diagnosis of X-linked disorders by sex determination only. PGD can offer some families the possibility of having children without the burden of any abortion at all.

\section{Prenatal testing: no option for parents of most DMD boys}

Prenatal diagnosis is offered only to women who have a known increased risk. A large proportion of women, 189/216 (88\%) who gave birth to a boy in the period 1993-2002 could not make use of this preventive measure, because the affected patient was the first in the family. This high percentage can be explained as follows. One in three DMD patients is thought to have a de novo mutation but empirical data show the number of de novo deletions, the most common type of mutation in the DMD gene, to be as high as $57 \%{ }^{11}$ Our own study indicates that a new mutation arose in $48 \%$. However, even if we consider the theoretical figure of one in three, one must remember that the mutation is de novo not only in one-third of the patients but also in one-third of the other two-thirds of the mothers who are carriers. In theory, therefore, the total number of DMD patients who are the first affected in the family is at least $56 \%$ $(1 / 3$ de novo in the patient plus $1 / 3 \times 2 / 3$ de novo in the carrier mother). This figure is remarkably close to the empirical data from the sixties where the percentage of sporadic DMD patients was $62 \%{ }^{7}$ Thus, the high number of sporadic DMD patients appears to be caused by the result of a relatively high rate of spontaneous mutations that have arisen in the mother, in the grandparents or in even earlier generations but which have not yet manifested in the birth of an affected offspring.

Prenatal diagnosis was also not an option for most of the remaining $12 \%(27 / 216)$ of the families with an older affected relative. Information about DMD in the older boy was not available at the time of birth in $26 / 27$, in nearly half of them (12) the older boy was younger than 5 years, the age at which DMD is generally diagnosed. The parents could have opted for prenatal diagnosis had they known about the older boy. To our knowledge, three studies have addressed the question of whether neonatal screening leads to 


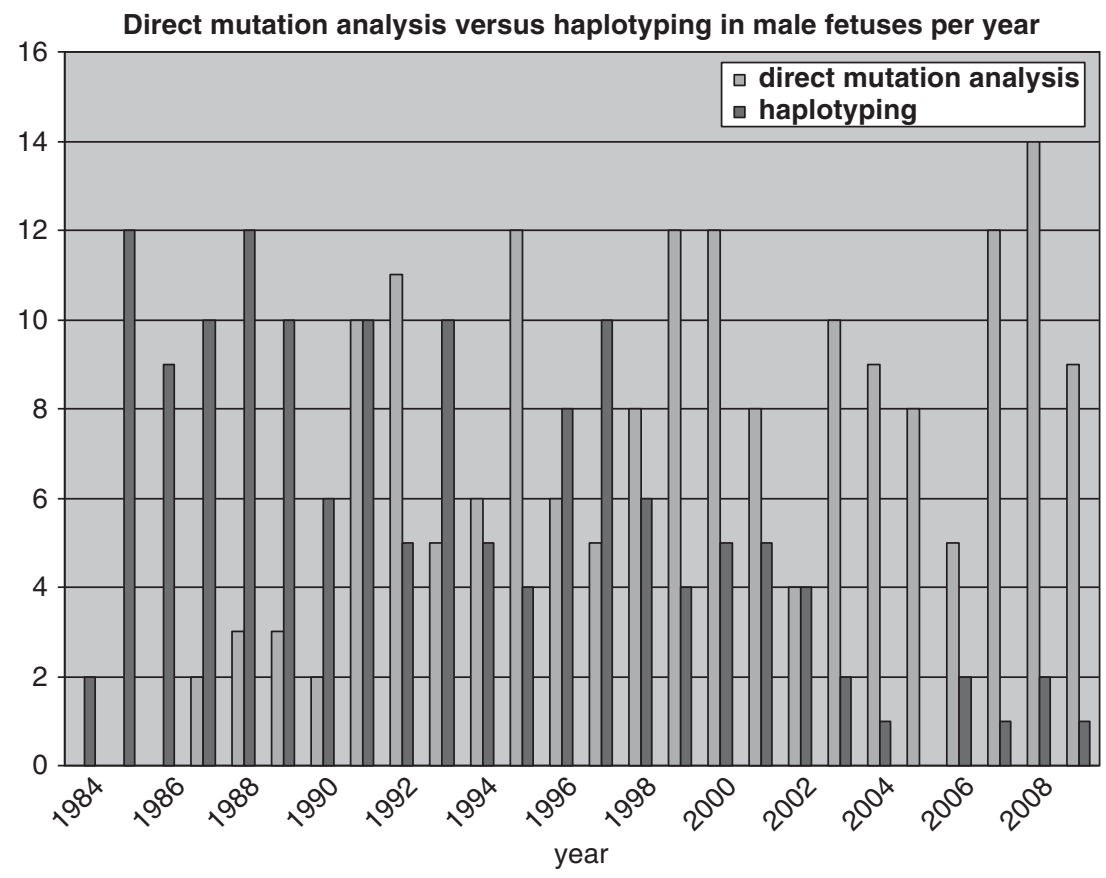

Figure 4 The number of male fetuses per year identified by direct mutation analysis and by haplotyping for an increased risk for DMD/BMD.

prenatal testing in subsequent pregnancies. A pilot study in 1993 showed that only $2 / 7$ pregnancies of a second child were monitored by prenatal diagnosis. The authors emphasize the influence of religion and/or extremely poor social conditions in the other five families. ${ }^{12}$ Two studies from 1998 have shown that families do assess their reproductive choices as a result of earlier diagnosis; $2 / 2$ and 10/12 subsequent pregnancies were monitored. ${ }^{13,14}$ Data from our prenatal cohort 1984-2009 (Figure 3) show that known DMD families do use prenatal diagnosis to prevent the birth of affected boys. A questionnaire held among DMD families in the Netherlands indicates that parents are in favor of early detection. ${ }^{15}$ Introduction of neonatal CK screening of males would improve the chances of prevention of DMD in the future.

\section{Increase in the percentage of first affected patients}

The proportion of first affected boys in the family has increased significantly from $62 \%$ in the birth cohort $1961-1974^{7}$ to $88 \%$ in the cohort 1993-2002. This indicates that the DMD families are more aware of their increased risk and have made use of prenatal tests to prevent the birth of a second affected boy as is shown in Figure 3. It is also possible that some families with one affected child may have decided not to have any more children.

\section{Female fetuses and carrier testing}

All professional recommendations agree that carrier testing of minors for X-linked recessive disease should ideally be deferred. ${ }^{16}$ The guidelines emphasize that the decision to test should be made by the child when it reaches the age of maturity because in general carrier testing has implications for the future reproductive prospects of that child only and not of her parents. This view is based on the basic ethical principle of informed consent, by which an individual can freely give, without external pressure, her/his consent to be tested after being informed of the benefits, risks, procedures and other pertinent information relating to the carrier test. It is not possible to predict whether or not a female heterozygous for a mutation in the $D M D$ gene will manifest any signs of the disorder. Also, being a carrier of DMD is not lethal, as it is for boys who are affected.
The current policy for DMD, therefore, is that female fetuses are not tested prenatally for carrier status. ${ }^{17}$ The parents are informed that their daughters can be tested from the age of 16, because from that age onward carrier females should be screened every 5 years for cardiomyopathy. ${ }^{18}$ However, in practice the vast majority of the girls $(78 \%)$ who are beyond the age of 16 years have not yet been tested (Figure 1). We have also shown that one in three women at risk of carrying a mutation in DMD families have not been tested. ${ }^{19}$ Further studies are planned to find out why potential carriers are not tested in these families.

One might say that the young potential carriers still have time to undergo carrier testing before having offspring as the average age for a woman to give birth to a first child in the Netherlands is 28 years (Statistics Netherlands, www.cbs.nl). However, that does not take into account the risk for cardiomyopathy, which is estimated to be around $10 \%$ at the age of 50 years; the youngest described carrier with cardiomyopathy in the Netherlands was 28 years. ${ }^{19,20}$ Furthermore, a recent study has shown that the cardiac abnormalities in carrier women are as progressive as in DMD patients. ${ }^{20}$ These women may not be aware of the risk and implications of being a carrier. For some women it may be too late as they may find out that they are carriers only after DMD is diagnosed in a son or after experiencing (sometimes severe) cardiac problems. $^{21}$ A proactive approach of using a genetic register service to contact the girls when they reach adulthood, as is done in the United Kingdom, ${ }^{22}$ should be considered.

Parents in DMD families have great difficulty in communicating with their children about the disease and its implications for the future. $^{23}$ They may struggle with the question of how to tell their daughter that she has a risk of being a carrier. Our study has shown that the average risk of being a carrier is $28 \%$. So, it is cruel to subject the parents to an ordeal, lasting years with this dilemma while the average chance of not being a carrier is $72 \%$. This problem could be solved if the parents are given the choice of having their daughters tested before adulthood at a time that is convenient for them, either neonatally or later. In the families where fetal sexing has been done on chorion villi or amniotic fluid and fetal DNA is available, the possibility of carrier testing on female fetuses should be offered. 


\section{Future prospects}

The majority of DMD patients are now the first in their family. So, prenatal diagnosis could not have been used as a means of prevention in these cases. Boys with a de novo mutation can only be detected if every pregnant woman is offered a prenatal test for the DMD gene. This is not realistic at present, but it may change in the future with the development of effective methods of testing the fetal genome in the maternal serum. ${ }^{24}$ The problem of de novo mutations in women could be solved by testing every prospective mother for mutations in the $D M D$ gene before conception, as is now increasingly possible for severe autosomal recessive diseases. ${ }^{25}$ However, this would require huge investments and is perhaps something for the future. Although prenatal screening has been used to prevent the birth of a second affected boy in the family, this was not possible in a large number of the cases because the older boy had not yet been diagnosed as he was younger than 5 years. For these cases, neonatal screening would seem the easiest solution at present.

The difficulty is that neonatal screening for an untreatable disease is prohibited by law in the Netherlands because of the requirement that the child in question should derive real benefit from screening. The situation may be about to change as treatments for DMD are now in an advanced stage of development; ${ }^{26-28}$ thus, neonatal screening may become feasible even under the current legal restrictions. With this expectation and the knowledge that the birth of the second affected child can be prevented perhaps a case could be made for introducing neonatal screening for boys sooner rather than later.

The most pressing matter for concern at present is that many girls have not been tested. Considering the arguments given above, we propose a change in policy, namely, that the parents should be given the choice of having their daughters tested either prenatally if possible or postnatally, also before adulthood when requested.

\section{CONCLUSIONS}

There was no significant change in the incidence of dystrophinopathies in the Netherlands as a result of prenatal testing and genetic counseling. However, we found evidence indicating that prenatal testing has been used by families to prevent the birth of a second affected boy. In the 26 years 145 male fetuses were aborted and 174 unaffected boys were born with the help of prenatal testing. Our study has revealed two problems: (1) A high proportion of families with de novo mutations in the $D M D$ gene cannot make use of prenatal diagnosis, exacerbated by the fact that older affected boys are usually not diagnosed before the age of five; (2) Current policy dictates that carrier testing is not done in female fetuses; the girls in DMD families may be tested at 16 years. In practice, however, $78 \%$ of these girls who are 16 years or older have not been tested. A carrier woman has a risk not only of having a son with DMD but also of having progressive cardiac disease herself. These facts, together with recent developments that suggest DMD could become treatable in the near future, point to an urgent need for a change in policy to improve the chances of prevention of DMD in the future. The first is to introduce neonatal CK screening of males and the second is to test females that are at risk for carrier status prenatally if fetal DNA is available or postnatally even before adulthood if requested by the parents.

\section{CONFLICT OF INTEREST}

The authors declare no conflict of interest.

\section{ACKNOWLEDGEMENTS}

We thank Professor Dr JJ Houwing-Duistermaat, Department of Medical Statistics and Bioinformatics, Leiden, for statistical support, Mrs M van Deursen-

Luijten, Department of Clinical Genetics, Maastricht, for providing the data on preimplantation genetic diagnosis, Ms T Cronenburg for collecting the data on the prenatal tests and of Ms $\mathrm{M}$ van der Lugt for digitizing the family trees.

1 Magri F, Govoni A, D'Angelo MG et al: Genotype and phenotype characterization in a large dystrophinopathic cohort with extended follow-up. J Neurol 2011; 258: 1610-1623.

2 Emery AE: Population frequencies of inherited neuromuscular diseases: a world survey. Neuromuscul Disord 1991; 1: 19-29.

3 Haldane JBS: The rate of spontaneous mutation of a human gene. J Genet 1935; 31 : 317-326.

4 Bakker E, Hofker MH, Goor $\mathrm{N}$ et al: Prenatal diagnosis and carrier detection of Duchenne muscular dystrophy with closely linked RFLPs. Lancet 1985; 1: 655-658.

5 de Die-Smulders CE, Geraedts JP, Dreesen JC, Coonen E, Land JA: Genetic diagnosis of IVF embryos: preliminary results from 'preimplantation genetic diagnoses' in the Netherlands. Ned Tijdschr Geneeskd 1998; 142: 2441-2444.

6 Almomani R, van der SN, Bakker E, den Dunnen JT, Breuning MH, Ginjaar IB: Rapid and cost effective detection of small mutations in the DMD gene by high resolution melting curve analysis. Neuromuscul Disord 2009; 19: 383-390.

7 van Essen AJ, Busch HF, te Meerman GJ, Ten Kate LP: Birth and population prevalence of Duchenne muscular dystrophy in The Netherlands. Hum Genet 1992; 88: 258-266.

8 Helderman-van den Enden AT, de Jong R, den Dunnen JT et al: Recurrence risk due to germ line mosaicism: Duchenne and Becker muscular dystrophy. Clin Genet 2009; 75: 465-472.

9 Dooley J, Gordon KE, Dodds L, MacSween J: Duchenne muscular dystrophy: a 30-year population-based incidence study. Clin Pediatr 2010; 49: 177-179.

10 Jeppesen J, Green A, Steffensen BF, Rahbek J: The Duchenne muscular dystrophy population in Denmark, 1977-2001: prevalence, incidence and survival in relation to the introduction of ventilator use. Neuromuscul Disord 2003; 13: 804-812.

11 Taylor PJ: Molecular genetic analysis of a New South Wales muscular dystrophy cohort. Dissertation 2008; http://handle.unsw.edu.au/1959.4/43309.

12 Hildes E, Jacobs HK, Cameron A et al: Impact of genetic counselling after neonatal screening for Duchenne muscular dystrophy. J Med Genet 1993; 30: 670-674.

13 Bradley D, Parsons E: Newborn screening for Duchenne muscular dystrophy. Semin Neonatol 1998; 3: 27-34.

14 Drousiotou A, loannou P, Georgiou T et al: Neonatal screening for Duchenne muscular dystrophy: a novel semiquantitative application of the bioluminescence test for creatine kinase in a pilot national program in Cyprus. Genet Test 1998; 2: 55-60.

15 Eilers R, Kleinveld JH, Vroom E, Westerman MJ, Cornel MC, Plass AC: Desirability of early identification of Duchenne Muscular Dystrophy (DMD): parents' experiences of the period prior to diagnosis. Eur J Hum Genet 2009; 18(supp 1): 374-375.

16 Borry P, Evers-Kiebooms G, Cornel MC, Clarke A, Dierickx K: Genetic testing in asymptomatic minors: background considerations towards ESHG recommendations. Eur J Hum Genet 2009; 17: 711-719.

17 Abbs S, Tuffery-Giraud S, Bakker E, Ferlini A, Sejersen T, Mueller CR: Best practice guidelines on molecular diagnostics in Duchenne/Becker muscular dystrophies. Neuromuscul Disord 2010; 20: 422-427.

18 Bushby K, Muntoni F, Bourke JP: 107th ENMC International Workshop: the manage ment of cardiac involvement in muscular dystrophy and myotonic dystrophy. 7th-9th June 2002, Naarden, the Netherlands. Neuromuscul Disord 2003; 13: 166-172.

19 Hoogerwaard EM, van der Wouw PA, Wilde AA et al: Cardiac involvement in carriers of Duchenne and Becker muscular dystrophy. Neuromuscul Disord 1999; 9: 347-351.

20 van Westrum SM, Hoogerwaard EM, Dekker L et al: Cardiac abnormalities in a followup study on carriers of Duchenne and Becker muscular dystrophy. Neurology 2011; 77: 62-66.

21 Davies JE, Winokur TS, Aaron MF, Benza RL, Foley BA, Holman WL: Cardiomyopathy in a carrier of Duchenne's muscular dystrophy. J Heart Lung Transplant 2001; 20 : 781-784.

22 Kerzin-Storrar L, Wright C, Williamson PR et al: Comparison of genetic services with and without genetic registers: access and attitudes to genetic counselling services among relatives of genetic clinic patients. J Med Genet 2002; 39: e85.

23 Plumridge G, Metcalfe A, Coad J, Gill P: Family communication about genetic risk information: particular issues for Duchenne muscular dystrophy. Am J Med Genet $A$ 2010; 152A: 1225-1232.

24 Lo YM, Chan KC, Sun $\mathrm{H}$ et al: Maternal plasma DNA sequencing reveals the genome wide genetic and mutational profile of the fetus. Sci Transl Med 2010; 2: 61ra91.

25 Bell CJ, Dinwiddie DL, Miller NA et al: Carrier testing for severe childhood recessive diseases by next-generation sequencing. Sci Trans/ Med 2011; 3: 65ra4.

26 Aartsma-Rus A: Antisense-mediated modulation of splicing: therapeutic implications for Duchenne muscular dystrophy. RNA Biol 2010; 7: 453-461.

27 Goemans NM, Tulinius M, van den Akker JT et al: Systemic administration of PRO051 in Duchenne's muscular dystrophy. N Engl J Med 2011; 364: 1513-1522.

28 Van Deutekom JC, Janson AA, Ginjaar HB et al: Local dystrophin restoration with antisense oligonucleotide PRO051. N Engl J Med 2007; 357: 2677-2686.
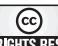

This work is licensed under the Creative Commons Attribution-NonCommercial-No Derivative Works 3.0 Unported License. To view a copy of this license, visit http:// creativecommons.org/licenses/by-nc-nd/3.0/ 